\title{
A case of immediate and delayed reactions after contact with a venomous mauve-stinger jellyfish in a diabetic patient
}

\author{
Laidon Shapo, Lance Saker
}

\begin{abstract}
Introduction: A contact with the venoms produced by a pelagic jellyfish type, known as Pelagia noctiluca, can induce both local and general symptoms. We report here a case of jellyfish envenomation with a mauve-stinger in a diabetic patient who developed localized skin involvement, delayed systemic reaction and hyperglycemia. To our knowledge this is the first report of this kind in literature. Case Report: The patient, an adult male tourist with type I diabetes, was stung on the forehead by a mauvestinger jellyfish while swimming on the Maltese coast in summer 2012. Local symptoms were initially of an erythematous, edematous and a vesicular topical lesion in the forehead region, followed by massive eye swelling 72 hours after the incident. In addition, his normally wellcontrolled diabetes was affected, with an unusual severe episode of hyperglycemia that did not respond readily to alterations in his insulin regime. Conclusion: Pelagia noctiluca is a jellyfish known for its strong cytotoxic properties. We hypothesize that the stress
\end{abstract}

Laidon Shapo ${ }^{1}$, Lance Saker ${ }^{2}$

Affiliations: ${ }^{1} \mathrm{MD}, \mathrm{MScPH}$, Public Health Strategist, Public Health for Camden and Islington, Camden Old Town Hall, Judd Street, London, WC1H 8NJ, United Kingdom; 2MBChB, FFPH, GP, Hampstead Group Practice and Camden CCG Consultant in Public Health, Camden Clinical Commissioning Group Stephenson House, 75 Hampstead Road, London, NW1 2PL, United Kingdom. Corresponding Author: Dr. Laidon Shapo, Public Health Strategist, Public Health for Camden and Islington Camden Old Town Hall, Judd Street, London WC1H 8NJ, United Kingdom; Tel: 0207527 8343; Email: Laidon.Shapo@islington.gov.uk

Published: 01 July 2013 response, following the jellyfish attack could have triggered a metabolic response and the consequences seen in this person with diabetes. The reaction described suggests that people with diabetes stung by $P$. noctiluca should monitor their glucose levels closely and in some cases seek treatment with more specialized endocrinology services.

Keywords: Jellyfish, Diabetes, Hyperglycemia

$$
* * * * * * * * *
$$

Shapo L, Saker L. A case of immediate and delayed reactions after contact with a venomous mauve-stinger jellyfish in a diabetic patient. International Journal of Case Reports and Images 2013;4(7):388-391.

$$
* * * * * * * * *
$$

doi:10.5348/ijcri-2013-07-338-12

\section{INTRODUCTION}

Jellyfish stings are common worldwide with an estimated 150 million cases annually $[1,2]$. The incidence appears to be rising due to the increasing marine activities of local populations, tourists and those who are involved in water activities. Jellyfish stings can cause a wide range of clinical manifestations ranging from skin inflammation to cardio-respiratory and other syndromes $[3,4]$.

In general, most stings cause a mild skin reaction. Persistent, delayed or recurrent episodes are less common. However, contact with the venoms produced by a small pelagic common purple jellyfish type populating Mediterranean waters, known as Pelagia noctiluca, is minimally toxic. Its stings usually cause local skin irritation or pain with most symptoms occurring immediately after the contact including local 
erythema, pain, pruritus, blistering, and swelling. Systemic complications, usually associated with exposure to a large amount of the toxin, are often limited to nausea, headache, and chills but could also lead to a major anaphylactic reaction. However, these are reported to be infrequent [5].

We report a case of jellyfish envenomation with P. noctiluca in a diabetic patient presenting with localized skin involvement and delayed systemic reactions and describe the treatment approach. Although case reports of jellyfish envenomation exist [2-4], we were unable to find any that reported on systemic effects in people with chronic conditions.

\section{CASE REPORT}

A white male, in his early 40s, with type I diabetes, was stung by a mauve-stinger P. noctiluca jellyfish (Figure 1) while swimming close to the shore off the Maltese coast near Mellieha bay in summer 2012.

The immediate reaction was of a sudden sharp pain in the forehead followed a few minutes later by dizziness. A large erythematous, Dedematous and vesicular lesion developed on the forehead over the next a few hours (Figure 2). These symptoms are characteristic of those usually described after contact with this species.

The affected area was treated at the Mellieha bay resort with white vinegar (5\%) for a few minutes and an ice pack was applied locally for another 15 minutes. As the patient was also feeling dizzy, he was advised to stay seated. An emergency treatment was initiated consisting of a single daily dose of antihistaminics (12 mg of chlorphenamine maleate for 3 days), to provide relief for the redness and swelling of the skin, and, painkillers (ibuprofen $400 \mathrm{mg}$ ) to ease the pain. The erythematous topical lesion was treated later with Benadryl cream (1\%) for one week. To date, some hyperpigmentation on the affected area is still present (Figure 3).

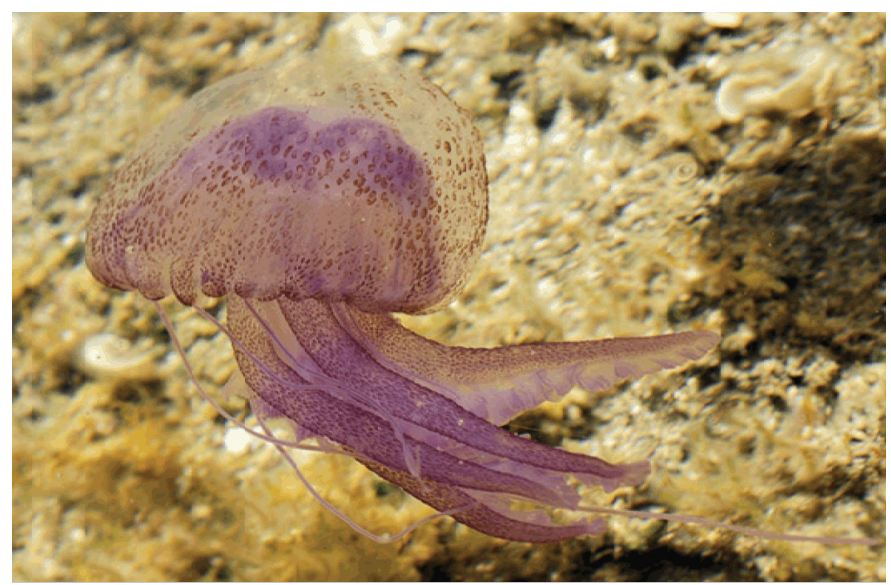

Figure 1: A mauve-pink jellyfish characteristic for Mediterranean Sea and seen on Maltese coast (P. noctiluca) Source: http://en.wikipedia.org/wiki/Pelagia_noctiluca
Delayed symptoms: Although the localized rash and edema at the forehead region eased after a couple of hours, the patient experienced massive eye swelling 72 hours later, probably a delayed reaction to exposure to P. noctiluca venoms. On day 4 , he was started on $10 \mathrm{mg}$ prednisone daily for 3 days reducing to $5 \mathrm{mg}$ for 2 days before stopping (i.e., a 5-day course). The dosage and duration took into account his underlying diabetes condition and in particular his sudden hypeglycemia after the incident, as described below.

Diabetes complications: This man has also type I diabetes. Usually, his glucose control is very good (average HbA1c level, in last year, around $7.2 \%$ ), but after being stung he experienced an immediate and severe hyperglycemic reaction. His glucose levels varied from $9 \mathrm{mmol} / \mathrm{L}$ to $13 \mathrm{mmol} / \mathrm{L}$ during the day, and, 12 $\mathrm{mmol} / \mathrm{L}$ to $16 \mathrm{mmol} / \mathrm{L}$ before breakfast with no changes in his diet, levels of physical activity or diabetes medication. Glucose levels did not normalize later despite him significantly increasing his daily intake of fast insulin (humalog) and basal insulin (lantus) from 32-40 IU/mL and from 50-56 IU/mL, respectively (tailored to pre-meal and before bed readings). Importantly, these changes occurred before the patient was started on prednisolone. Once steroid was commenced on day-4, the patient monitored blood glucose levels and adjusted insulin doses even more closely; however, both blood glucose and insulin

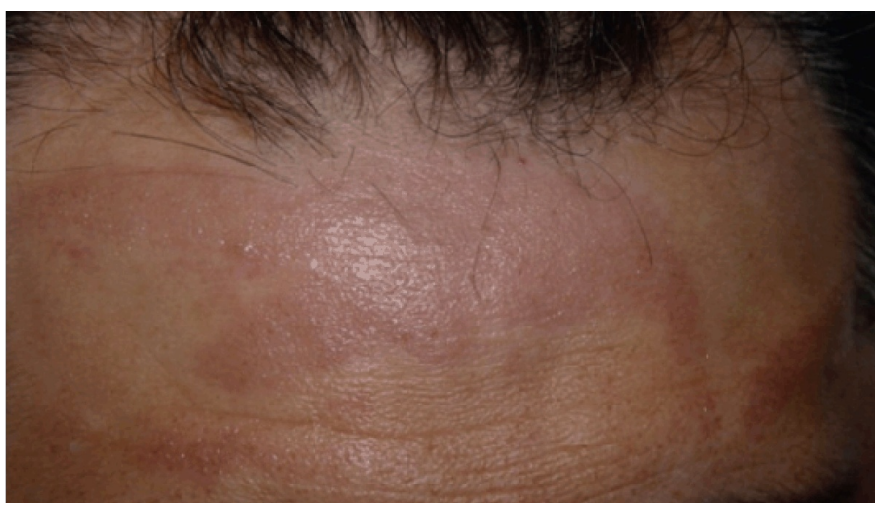

Figure 2: The jellyfish sting causing an evident erythematous topical lesion in the forehead (a few hours after initial treatment received).

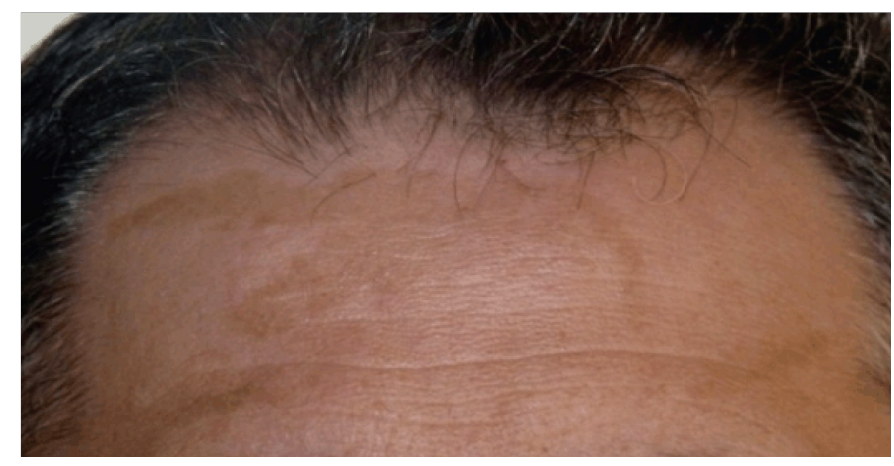

Figure 3: Residual skin hyperpigmentation in the affected area (a few months later). 
requirements only returned to normal at the end of the first week, once local and general symptoms related to the jellyfish sting eased (at which point the patient was still taking prednisolone). The hyperglycemic episode did not require hospitalization.

\section{DISCUSSION}

Pelagia noctiluca is known for its potent venom [6]. The characteristic delayed histological features found in such cases are dense superficial perivascular infiltrate of lymphocytes and eosinophils associated with edema of the papillary dermis, for which it has been suggested Langerhan's cells and T lymphocytes may play a central role [7]. The skin lesions seen on this patient were a result of contact with this particular cnidarians.

Systemic complications after someone is stung by P. noctiluca are reported to be infrequent [5]. The pain produced in this patient might be due to the reaction of exogenous or endogenous mediators on cutaneous nerves most likely due to a kinin-like factor [7].

These marine species are known to express strong cytotoxic properties [8]. The mechanisms whereby the venoms of $P$. noctiluca induce the cytotoxic effect are still not fully understood. Although some in vitro studies suggest its toxins may induce oxidative stress, it is not clear how this could lead to further metabolic changes in diabetic patients [9]. However, the available evidence suggests that hyperglycemia is known to develop as a normal and protective response to stress and trauma [10]. We hypothesize that in this case, the stress response to jellyfish trauma triggered a metabolic reaction raising plasma catecholamines and glucocorticoids, which in turn led to the short lived though significant episode of hyperglycemia [11]. Similar changes have been described in patients with burns and other serious injuries [12].

Although jellyfish stings are common, many general practitioners and other clinicians are unfamiliar with their management. Cutaneous injuries by any cnidarians have a myriad of clinical presentations but most are self limiting and only require symptomatic treatments that include simple steps to deactivate the nematocysts and control the pain. Dealing with delayed reactions and systemic complications often require specific measures of control and in more complex cases hospitalization $[13,14]$.

\section{CONCLUSION}

As per our experience with this case any diabetic patient stung by one of these marine creatures should also monitor carefully their glucose control, particularly if they experience severe local reactions or systemic symptoms. Supplemental and/or correctional insulin may be required to control hyperglycemia. It is possible that patients with other endocrine conditions may experience similar disturbances in their metabolic control.

\section{ACKNOWLEDGEMENTS}

We would like to thank: Dalya Marks, Public Health Strategist (Long-term conditions) at NHS North Central London, London Borough of Camden; and, Prof. Paul O'Flynn, Consultant ENT/ Head \& Neck Surgeon at University College Hospital London, for their contribution in providing useful comments and supporting this work.

$$
* * * * * * * * *
$$

\section{Author Contributions}

Laidon Shapo - Substantial contributions to conception and design, Acquisition of data, Analysis and interpretation of data, Drafting the article, Revising it critically for important intellectual content, Final approval of the version to be published

Lance Saker - Analysis and interpretation of data, Revising it critically for important intellectual content, Final approval of the version to be published

\section{Guarantor}

The corresponding author is the guarantor of submission.

\section{Conflict of Interest}

Authors declare no conflict of interest.

\section{Copyright}

(C) Laidon Shapo et al. 2013; This article is distributed under the terms of Creative Commons Attribution 3.0 License which permits unrestricted use, distribution and reproduction in any means provided the original authors and original publisher are properly credited. (Please see www.ijcasereportsandimages.com /copyright-policy.php for more information.)

\section{REFERENCES}

1. Boulware DR. A randomized controlled field trial for the prevention of jellyfish stings with a topical sting inhibitor. J Travel Med 2006;13(3):166-71.

2. Al-Rubiay K, Al-Musaoi H, Alrubaiy L, Al-Freje M. Skin and systemic manifestations of jellyfish stings in Iraqi fishermen. Libyan J Med 2009;4(2):75-7.

3. Bianchi R, Torella D, Spaccarotella C, Mongiardo A, Indolfi C. Mediterranean jellyfish sting-induced Tako-Tsubo cardiomyopathy. Eur Heart J 2011;32(1):18.

4. Pang KA, Schwartz MS. Guillain-Barré syndrome following jellyfish stings (Pelagia noctiluca). J Neurol Neurosurg Psychiatry 1993;56(10):1133.

5. Mariotinni GL, Giacco E, Pane L. The mauve stinger Pelagia noctiluca (Forskål, 1775). Distribution, ecology, toxicity and epidemiology of stings: a review. Mar Drugs 2008;6(3):496-513.

6. Mariottini GL, Sottofattori E, Mazzei M, Robbiano L, Carli A. Cytotoxicity of the venom of Pelagia noctiluca forskål (Cnidaria: Scyphozoa). Toxicon 2002;40(6):695-8. 
7. Menahem S, Shwartzman P. Recurrent dermatitis from jellyfish envenomation. Canadian Family Physician 1994;40:2116-8.

8. Ayed Y, Boussabbeh B, Zakhama W, Bouaziz Ch, Abid S, Bacha H. Induction of cytotoxicity of Pelagia noctiluca venom causes reactive oxygen species generation, lipid peroxydation induction and DNA damage in human colon cancer cells. Lipids in Health and Disease 2011;10:232-5.

9. Morabito R, Condello S, Currò M, Marino A, Ientile R, La Spada G. Oxidative stress induced by crude venom from the jellyfish Pelagia noctiluca in neuronal-like differentiated $\mathrm{SH}_{-} \mathrm{SY}_{5} \mathrm{Y}$ cells. Toxicol In Vitro 2012;26(5):694-9.

10. Eakins J. Blood glucose control in trauma patients. J Diabetes Sci Technol 2009;3(6):1373-6.

11. Mecott GA, Al-Mousawi AM, Gauglitz GG, Herndon DN, Jeschke MG. The role of hyperglycemia in burned patients: evidence-based studies. Shock 2010;33(1):5-13.

12. Gauglitz GG, Herndon DN, Jeschke MG. Insulin resistance postburn: underlying mechanisms and current therapeutic strategies. J Burn Care Res 2008;29(5):683-94.

13. Daubert GP. Cnidaria envenomation. Emedicine article. Available online at: http://emedicine.medscape.com/article/769538overview (Updated Nov. 2012).

14. Khardori R. Type 1 Diabetes Mellitus Treatment \& Management. Emedicine article. Available online at: http://emedicine.medscape.com/article/117739treatment (Updated. Dec. 2012).
Access full text article on other devices

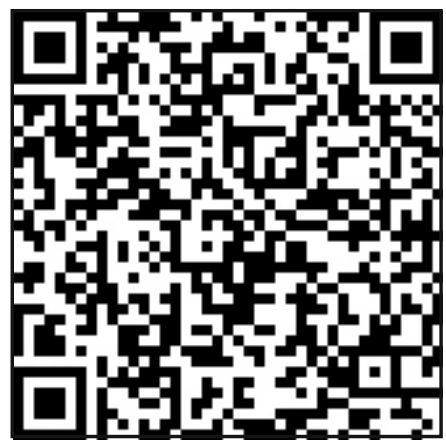

Access PDF of article on other devices

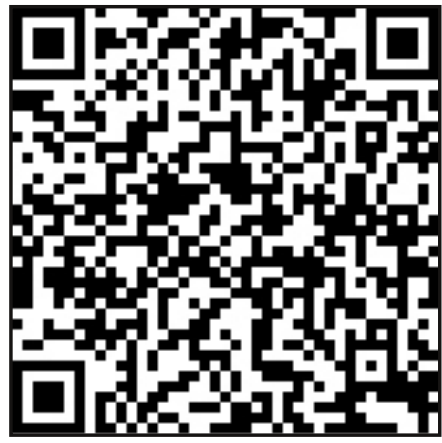

